\title{
Design and Development of Fan Speed and Light Speed Control Systems with Android-Based Voice Commands
}

\author{
Anna Nur Nazilah Chamim ${ }^{*}{ }^{1}$, Rama Okta Wiyagi ${ }^{1}$, Karisma Trinanda Putra ${ }^{1}$, Faruliyan Arya \\ Ferisnanda $^{1}$, Yessi Jusman ${ }^{2}$ \\ ${ }^{1}$ Department of Electrical Engineering, Faculty of Engineering, Universitas Muhammadiyah \\ Yogyakarta) \\ Bantul 55183 Daerah Istimewa Yogyakarta, Indonesia \\ ${ }^{2}$ Department of Informatics Engineering, Faculty of Engineering \\ Universitas Abdurrab, Pekanbaru, Riau, Indonesia \\ *Corresponding author, e-mail: anna_nnc@umy.ac.id
}

\begin{abstract}
At this time controlling electrical equipment in the form of fans and lights are still mostly using conventional switches. By using an android voice command device with a bluetooth connection, controlling the equipment can be easier. Using a Bluetooth connection will reduce the use of cables and speed up the process of activating or deactivating electronic devices because they do not have to get close to reach the switch. With input in the form of voice commands is very easy in controlling electronic devices such as fans and lights. With the adjustment of the fan speed and brightness of the lights with voice commands can save electricity and more easily in its settings.
\end{abstract}

Keywords: Speech recognition, Android, Lights, Fans

\section{Introduction}

One of the goals of developing technology is to help human work in daily life. Many electronic devices are controlled very often such as controlling fans or lights and other electronic equipment. At this time the control of electronic equipment is still mostly using manual control with a switch. As in the control of the fan and house lights are still largely controlled by ordinary switches.

Control of fans and lights in the room by using a switch requires humans to approach and reach the switch to control it. Based on this the author wants to design a control system for electrical equipment in the form of fans and lights with voice commands. The development of smart phones or Android smartphones can be used as a voice command data sender via Bluetooth connected to an arduino microcontroller to control electrical equipment in the form of fans and lights.

According to Gerry Indryan Pratama (2014) in his paper entitled "Control System with Voice
Commands Using Android Smartphones on Arduino-Based Ship Robots" states that by using the voice command feature found on smartphones with Android operating system and using the voice command application that has been made, users can control Arduino-based Ship Robots only by giving voice commands in the form of "Forward", "Right", "Left" and "Stop". Voice commands entered by the cellphone will be matched on Google Server then the results by the cellphone will be sent via bluetooth cellphones to the bluetooth contained in the ship's robot. The results of tests carried out by ship robots can be controlled properly through voice command applications that are implanted on smart phones. The robot can move forward, turn right, turn left and stop according to the voice commands given by the user [1].

According to Mohamad Amirudin Latief (2015) in his paper entitled "Voice Command Control of Household Electronic Devices Using Resberry Pi" states that human speech or speech is the most common way of communicating by humans. In his research carried out experimentally and can prove 
that the control of household electronic devices can be controlled by voice commands via a smartphone [2].

Based on the above problem formulation, this research provide the purpose of designing the tool to create an application on an Android smartphone so that it can be used to give voice commands or voice commands via Bluetooth to control fan speed and brightness of the lights.

\section{Methods}

Flowchart for this research is presented in Fig 1:

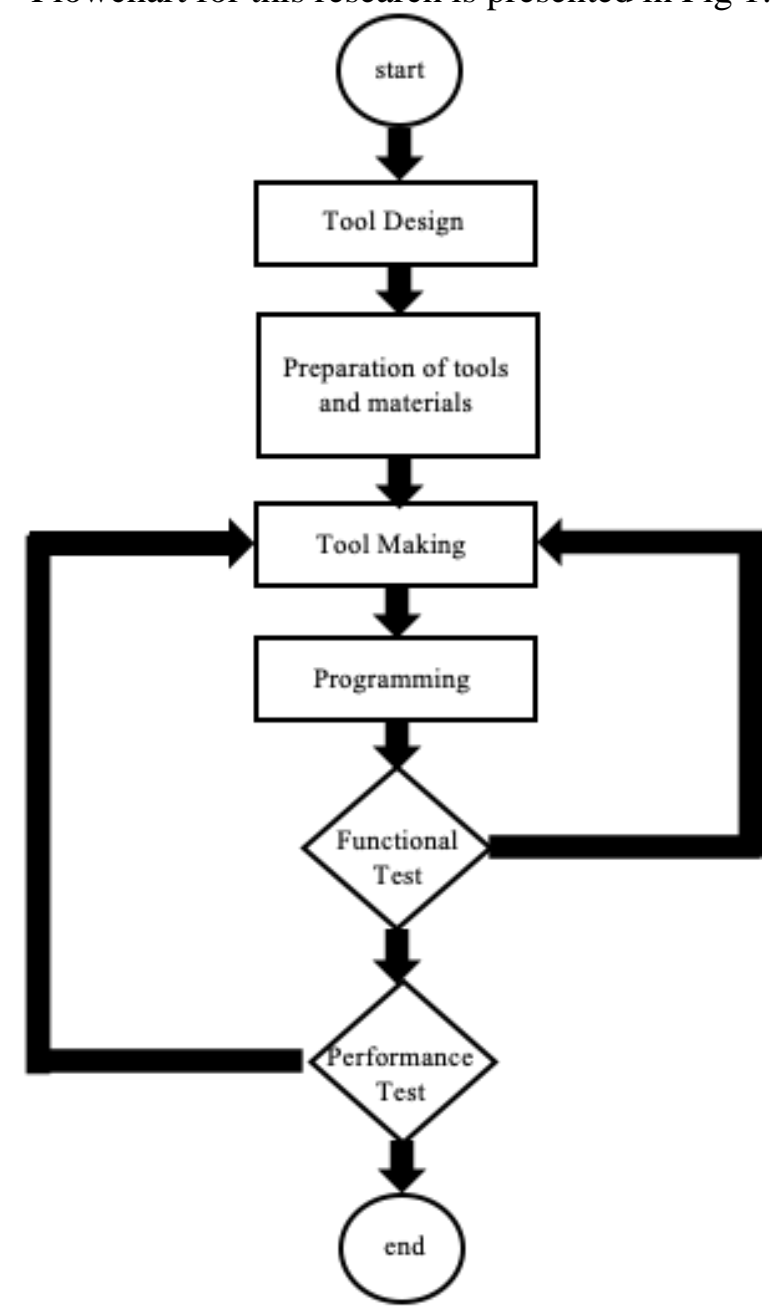

Fig. 1. Research Flow Chart

\section{Results}

\section{III.1. Planning Results}

\section{Hardware Manufacturing}

In the results of making this hardware the author makes a box design that is used as a processing device and load driver. With the use of this box, it will improve in terms of security and then make it easier to operate and can look more presentable when used. The design and hardware results that have been made as presented in Figures 2 and 3:

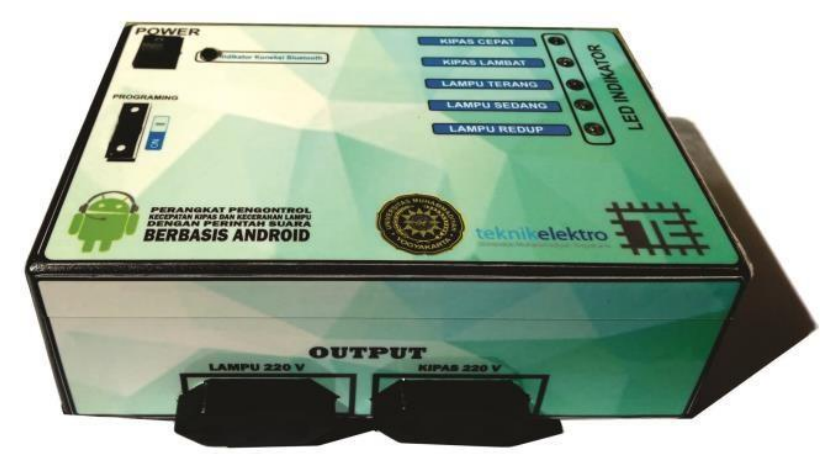

Fig. 2. Box looks front and top

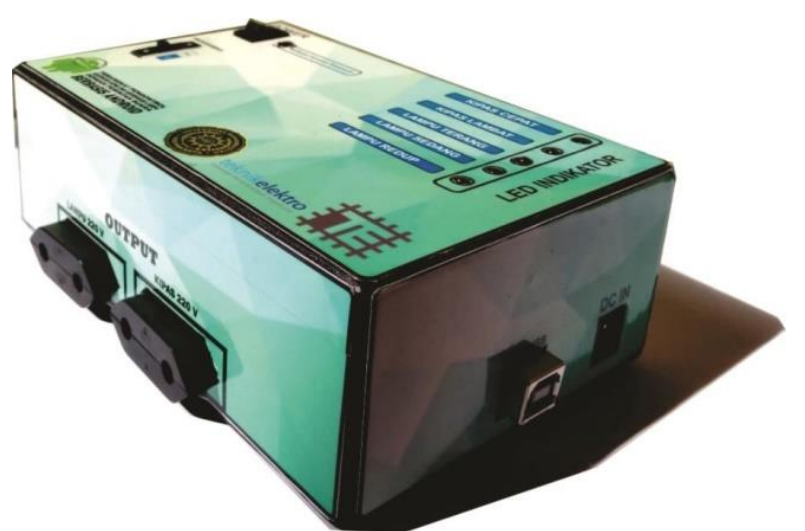

Fig. 3. Box looks right and top side

2. The results of making Android applications

In making this android application the author uses the App Inventor software on an online computer. In general, the function of this application is as a voice command input device by activating the speech recognition function then the data that has been obtained is sent to Arduino via a Bluetooth connection and then processed for load management.

The appearance of the android application on the smartphone that the author makes is shown in Figure 3.

If the control entry button is pressed, the first screen will move to the next screen, which is the control screen. The controlling screen image in this application is shown in Figure 4.

In Figure 5, a screen is displayed using the voice command application. This display is a control display that will be used to control the load with voice commands. At the top there is a Bluetooth connection button, if Bluetooth is not connected 
then the text "TIDAK TERKONEKSI (NOT CONNECTED)" appears red and when connected will appear the words "TERKONEKSI (CONNECTED)" colored green. The blutooth button is also used for pairing with Bluetooth on a controller device. There is a button in the form of a mic image, this button functions to call speech recognition as an input device. Besides being activated by clicking on the speech recognition function, it can also be activated by shaking the cellphone because the writer activates the accelerometer sensor function in this application. List of sound orders is presented in Table I.

TABLE I

LIST OF VOICE COMMANDS

\begin{tabular}{cc}
\hline \multicolumn{2}{c}{ LIST OF VOICE COMMANDS } \\
\hline \hline Command & Information \\
\hline "Hidupkan Semua" & Turn on the lights and fan \\
"Matikan Semua" & Turn off the lights and fan \\
"Lampu Terang" & Turn on the bright light \\
"Lampu Sedang" & Turn on the medium light \\
"Lampu Redup" & Turn on the dim light \\
"Kipas Cepat" & Turn on the fast fan \\
"Kipas Lambat" & Turn on the slow fan \\
"Matikan Lampu" & Turn off the light \\
"Matikan Kipas" & Turn off the fan \\
\hline \hline
\end{tabular}

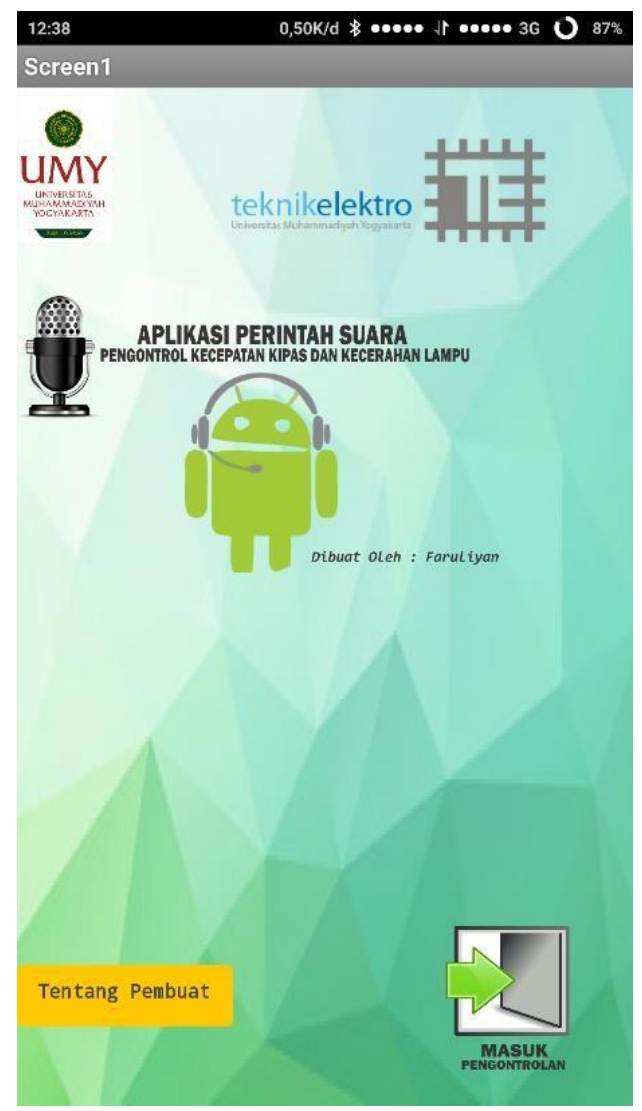

Fig. 4. The initial display of the voice command application

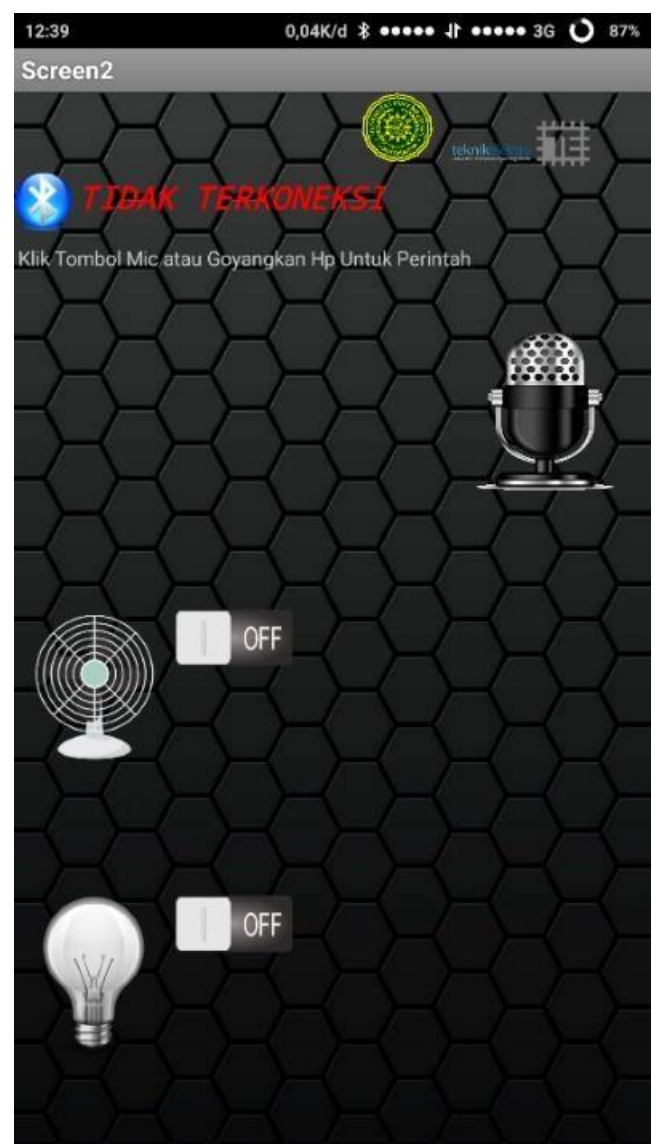

Fig. 5. Voice control application display control

\section{III.2. Performance Testing Tools}

1. Testing the performance of the tool at the fan load

a. Fast Fan Command

When the fast fan command is given, the load in the form of a $220 \mathrm{VAC}$ fan will spin optimally and the fast fan led indicator will light up. In this command the smartphone will send data via Bluetooth to Arduino for setting the fan load to get the maximum voltage so the fan rotation can be fast.

Arduino will process the incoming data and then adjust the PWM signal amount which will regulate TRIAC so that the maximum fan load voltage is obtained, that is on 255 on the PWM. With a maximum PWM, the fan rotation will rotate at the fastest rotation. The test results are in Figures 6 and 8 .

The LED indicator is used to find out which command is being run on this tool. If all LED indicators are off, the load is also off. There are 5 number of LED indicators for 3 lamp load conditions and 2 fan load conditions. 


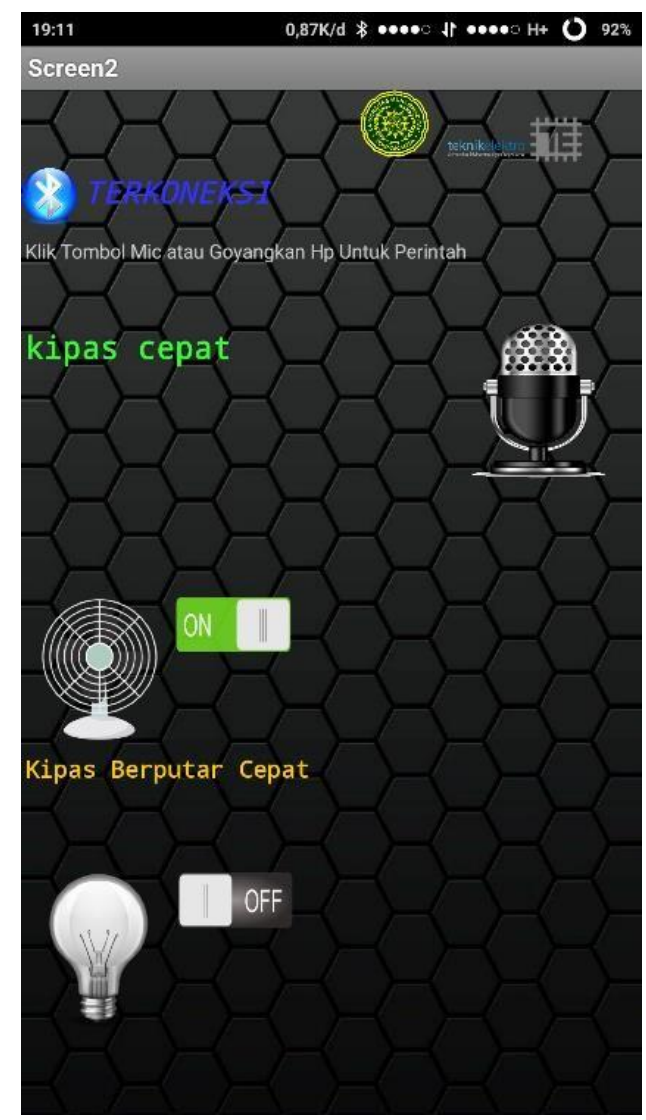

Fig. 6. Display applications when the fan is fast

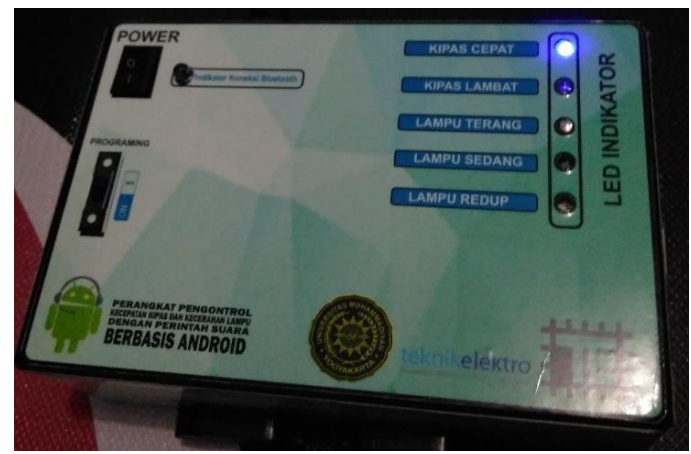

Fig. 7. LED indicator when the fan is fast

\section{b. Slow Fan Command}

When the slow fan command is given, the load in the form of a $220 \mathrm{VAC}$ fan will spin less than the maximum and the slow fan led indicator will light up. Display applications is presented in Figure 9.

After the slow fan command is given, there will be an indicator displayed on the application display and an LED indicator on the load device. LED indicator is presented in Figure 10.

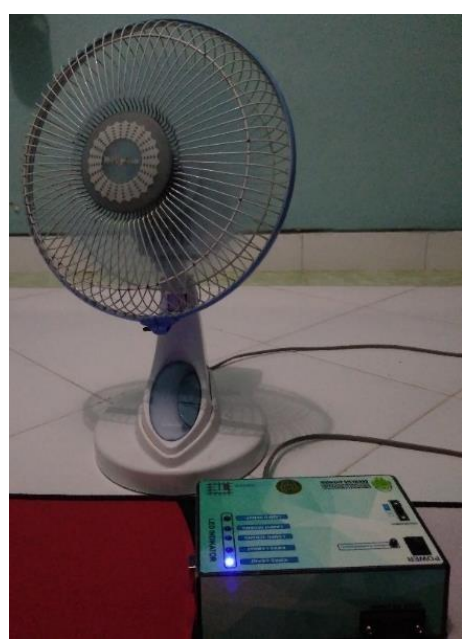

Fig. 8. Fan rotates fast

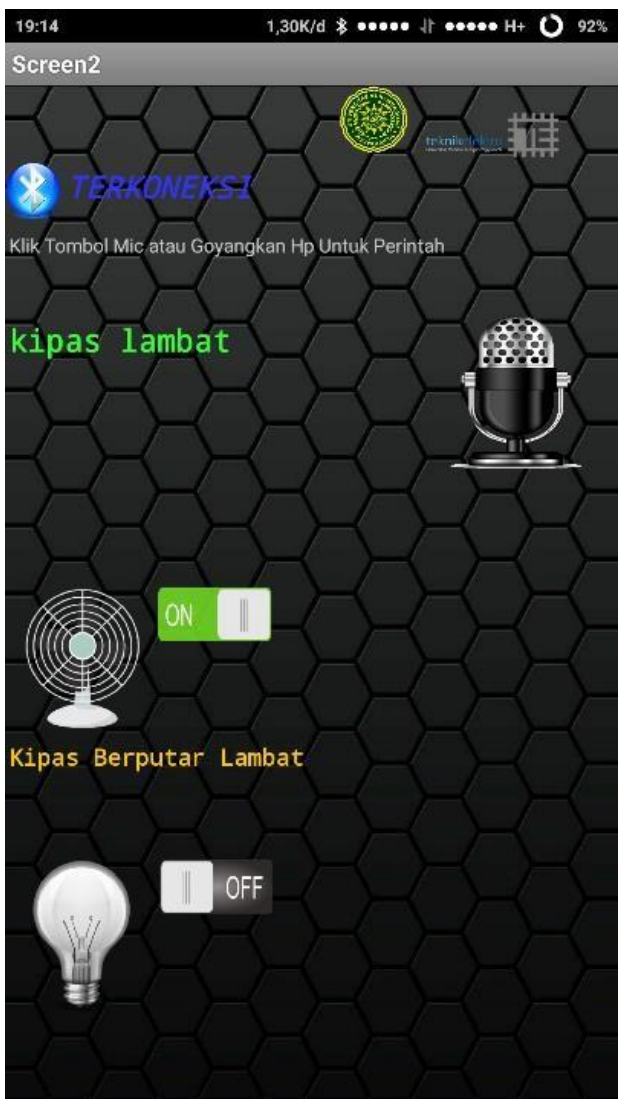

Fig. 9. Display applications when the fan is slow

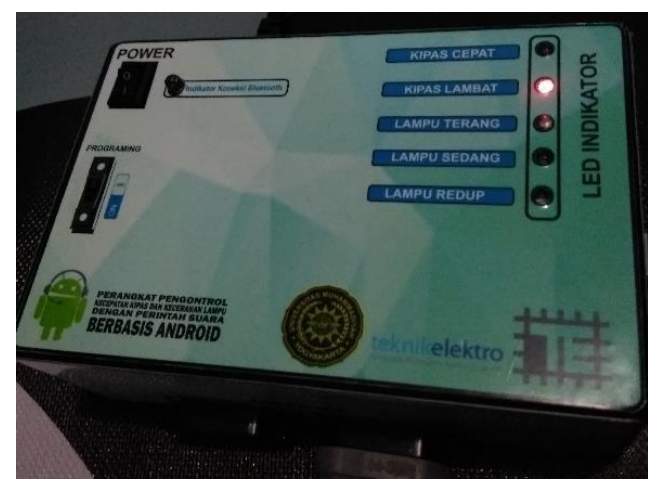

Fig. 10. LED indicator when the fan is slow

Journal of Electrical Technology UMY, Vol. 2, No. 2 


\section{c. Turn off the Fan Command}

When this command is given, the fan load will stop rotating and there will be an indicator that appears on the application screen or the LED indicator on the load device will turn off. The test results are in Figures 11 and 12.

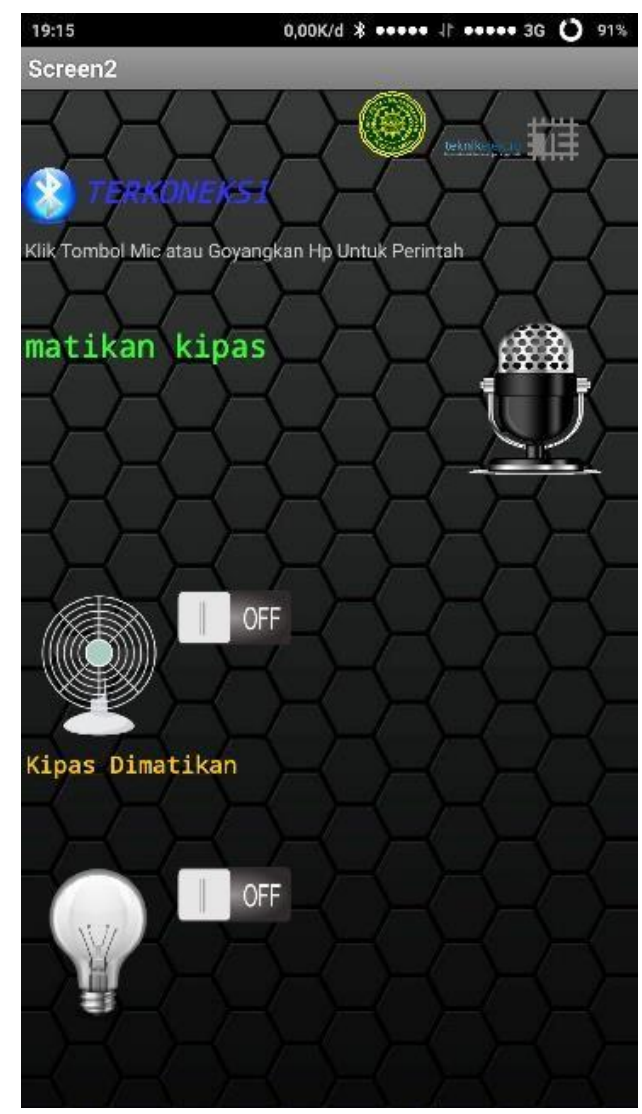

Fig. 11. Display applications when the fan is turned off

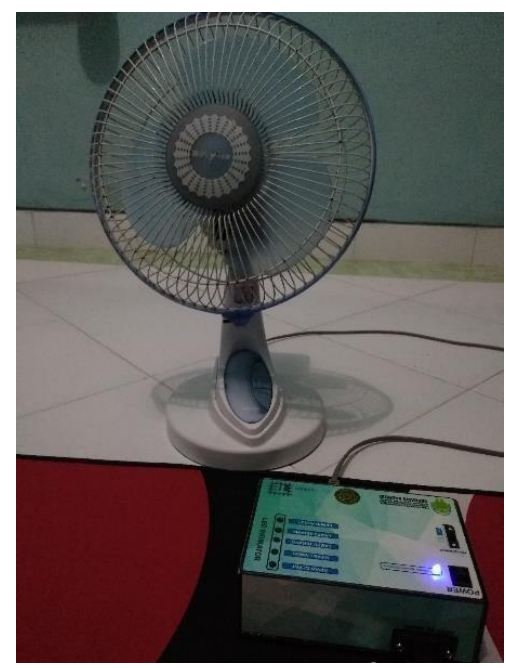

Fig. 12. Fan is turned off

2. Testing the performance of the tool at the light load

In this test carried out using a 220VAC 8 watt
LED lamp load. Tests carried out to be able to find out whether the tool can control the lamp load properly as expected. The tests are as follows:

a. Bright Light Command

A bright light command is used to give a command so that the load on the lamp is given the maximum voltage so that the light on the lamp is given the maximum light. With this command, Arduino gives a signal to the TRIAC input connected to the zero crossing circuit to be activated at a value of $1.3 \mathrm{~ms}$. The test results are in Figures 13 and 14.

b. Medium Light Command

In giving the command this medium lamp aims to provide a medium voltage output on the lamp load so that the light produced is medium light. The test results are in Figures 15 and 16.

c. Dim Light Command

Giving a dimmer command is a command to provide a low voltage output on the lamp load to get the results of the dim light. The test results are in Figures 17 and 18.

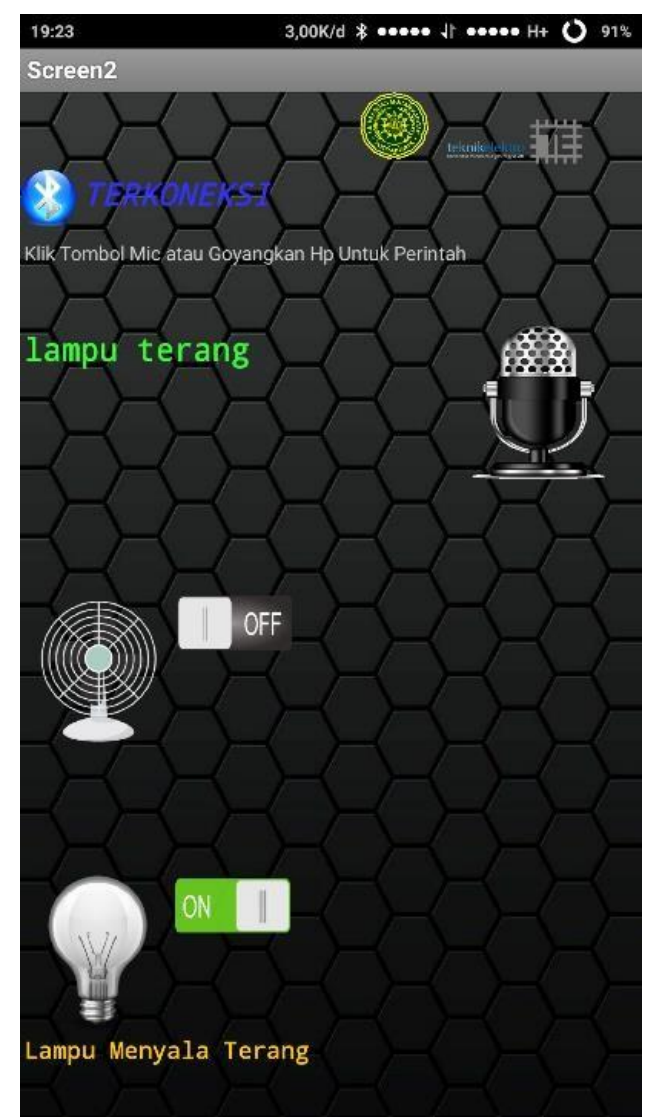

Fig. 13. Display applications when the light is bright

Journal of Electrical Technology UMY, Vol. 2, No. 2 


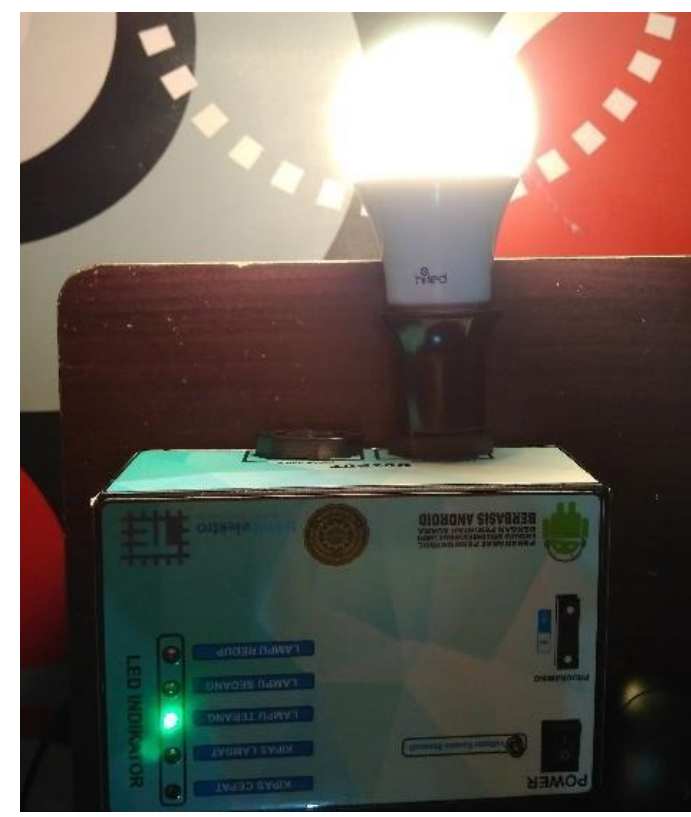

Fig. 14. LED indicator when the light is bright

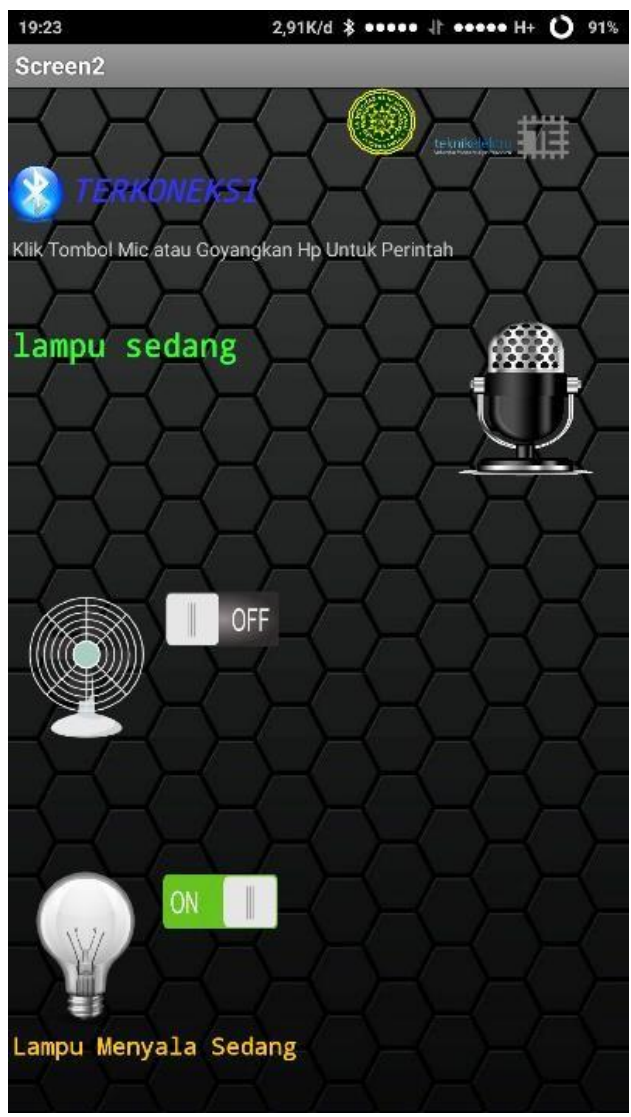

Fig. 15. Display applications when the light is medium

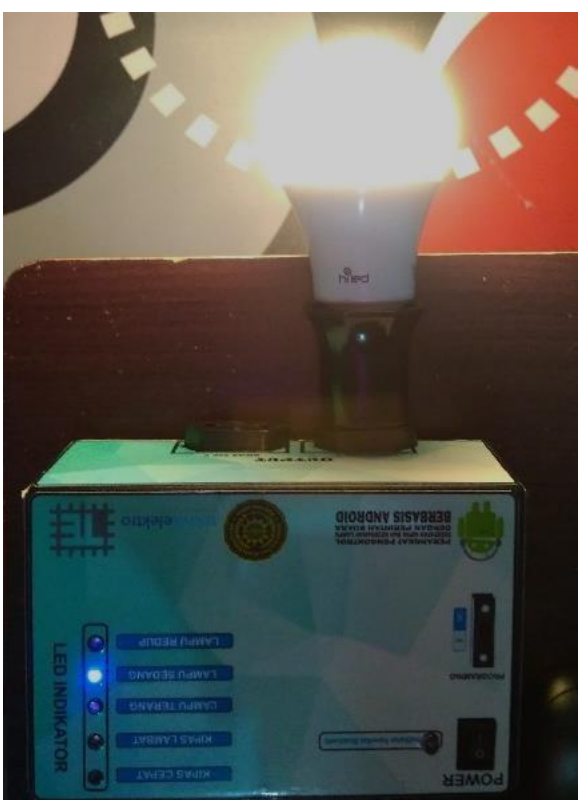

Fig. 16. LED indicator when the light is medium

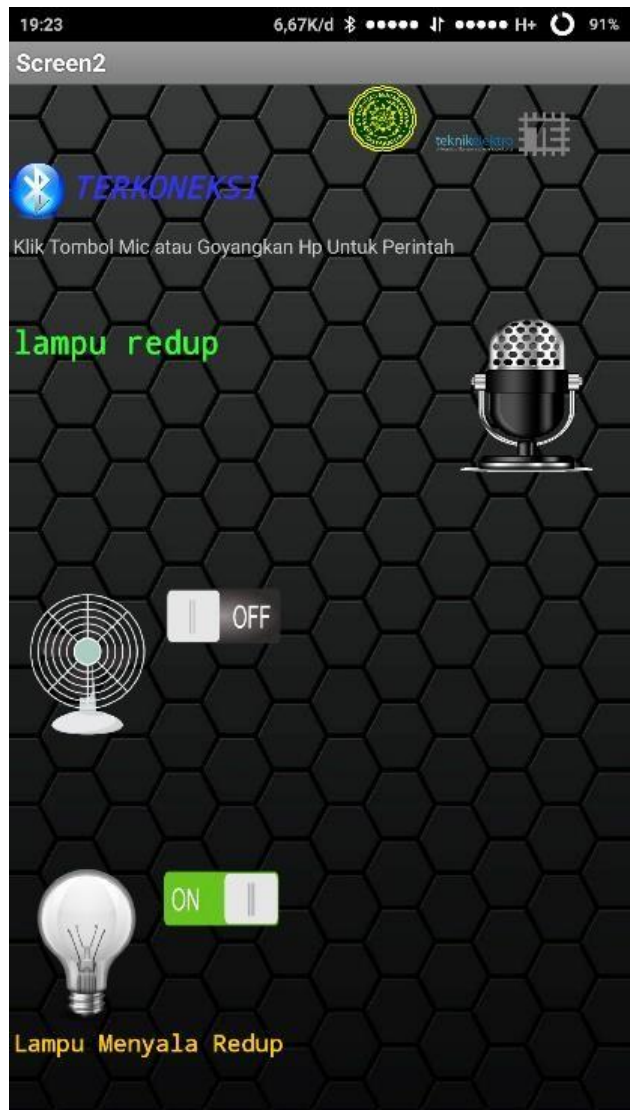

Fig. 17. Display applications when the light is dim 


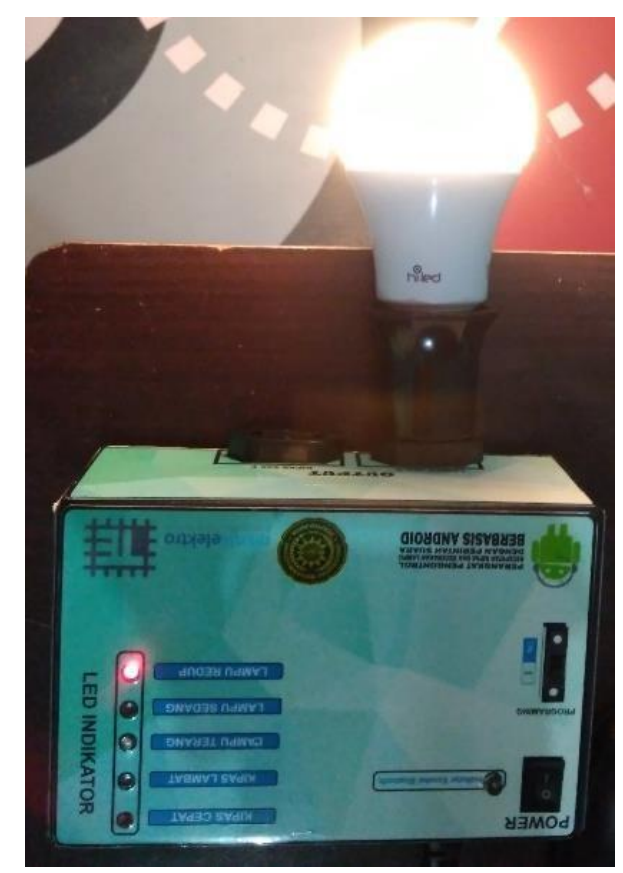

Fig. 18. LED indicator when the light is dim

\section{d. Turn off the Light Command}

The command to turn off the lamp is used to disconnect the output voltage on the lamp load so that the lamp does not turn on. Display applications is presented in Figure 19.

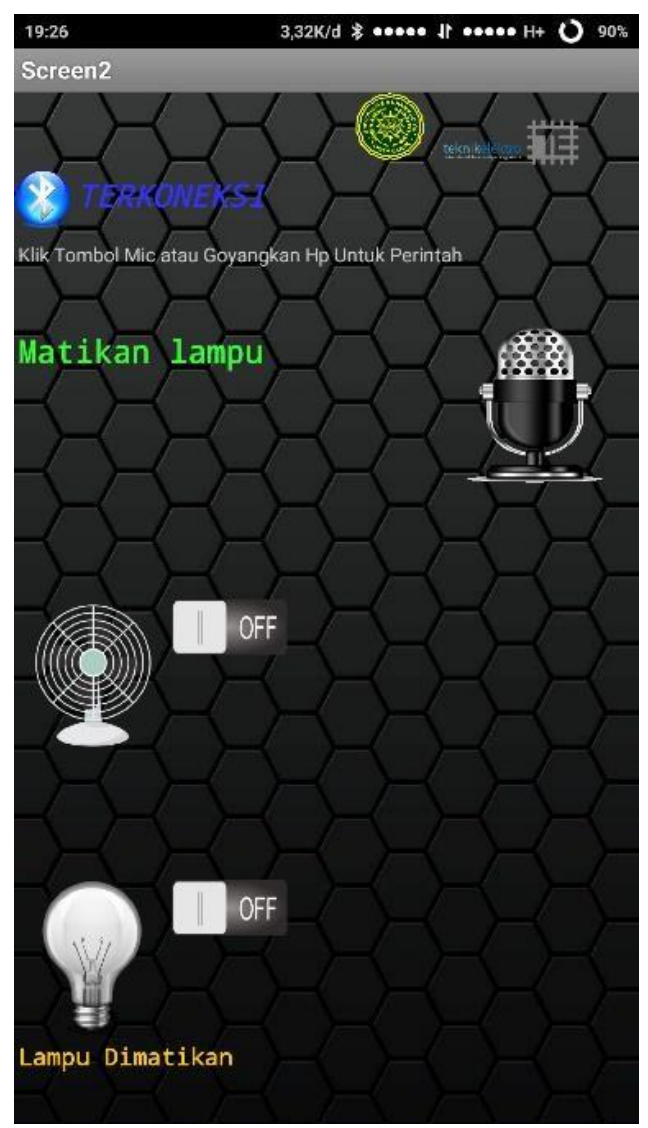

Fig. 19. Display applications when the fan is turned off
3. Testing the performance of the tool at the fan and lamp load

With the command turn on all, the fan load and the lamp will be active at all maximum conditions. Then in the command turn off all the two loads will turn off. The test results are in Figures 20 and 21.

The next performance test is testing the distance of the instrument control range. By using a Bluetooth connection, this device has limited range control. The use of a bluetooth connection is used because of the ease of use and the ease of use of the bluetooth module used.

The range of the Bluetooth connection on devices on the market is around $10 \mathrm{~m}$. The range of the Bluetooth connection is very influential on the area used in this device. If the area is blocked by objects or walls it will affect the distance of the Bluetooth range. In testing this tool is not blocked by a wall.

The measurement data for the distance of this tool can be seen in the following Table II.

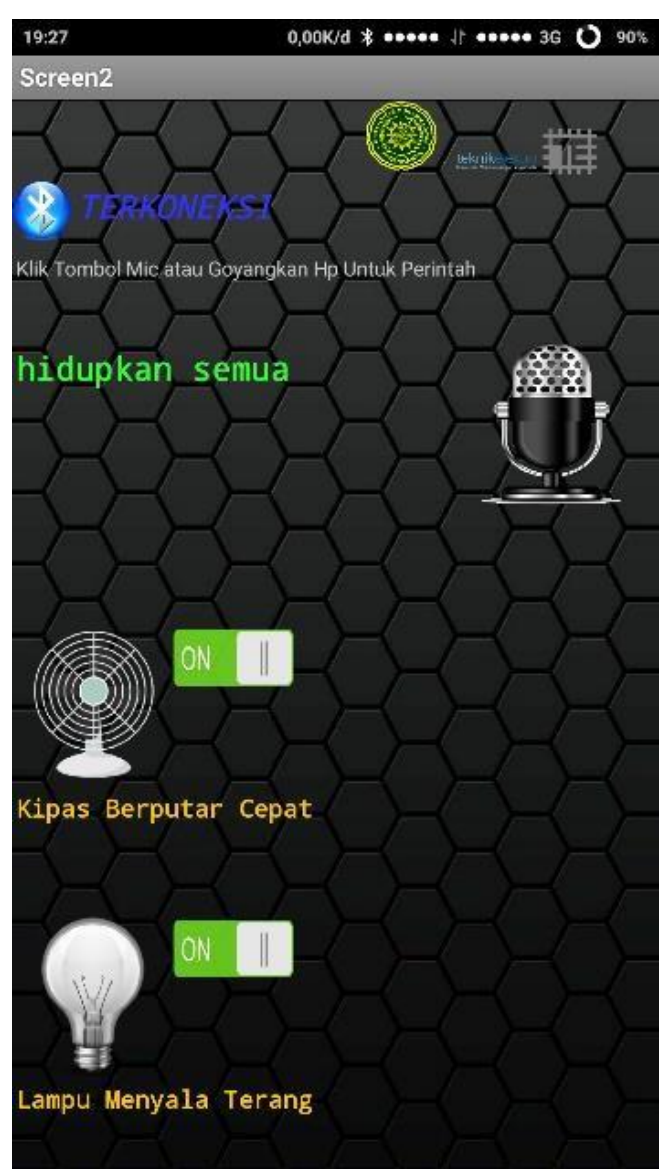

Fig. 20. Display applications when the fan and light are turned on 


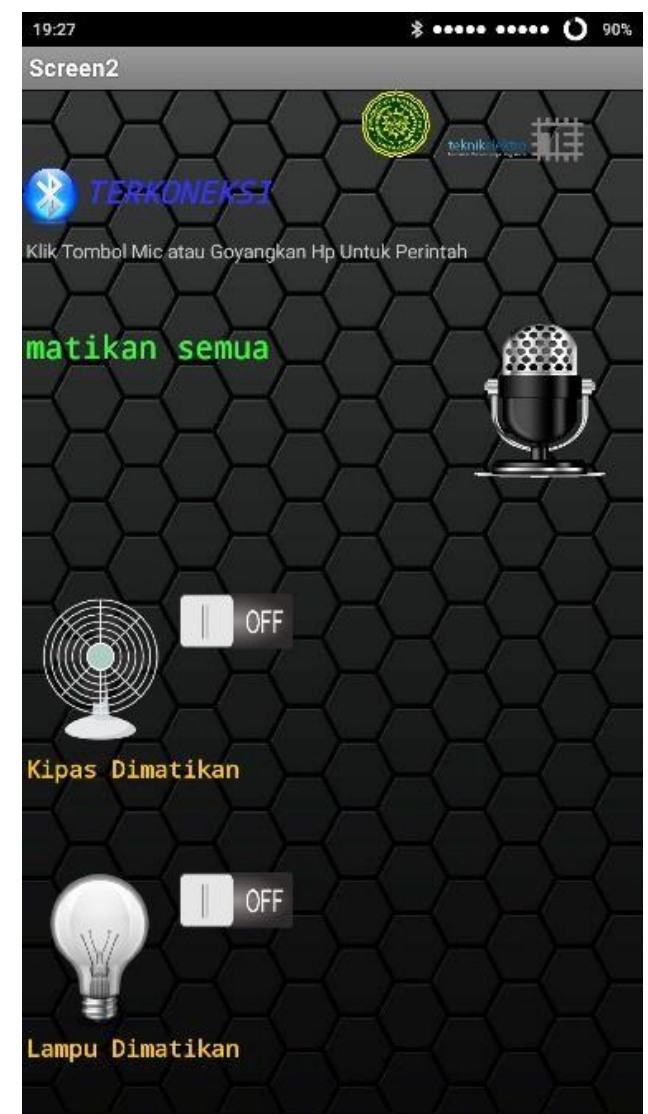

Fig. 21. LED indicator when the fan and light are turned off

TABLE II

BLuetooth Connection Distance CAPABILity

\begin{tabular}{cc}
\hline \hline Distance & Connection \\
\hline 1 meter & Connected \\
2 meter & Connected \\
3 meter & Connected \\
4 meter & Connected \\
5 meter & Connected \\
6 meter & Connected \\
7 meter & Connected \\
8 meter & Connected \\
9 meter & Connected \\
10 meter & Connected \\
11 meter & Not Connected \\
\hline \hline
\end{tabular}

Experimental data from several people who gave voice commands can be seen in Table III.

TABLE III

LisT OF APPLICATION TESTERS

\begin{tabular}{ccc}
\hline \multicolumn{2}{c}{ LIST OF APPLICATION TESTERS } \\
\hline Name & Gender & Connection \\
\hline Popi & Female & Connected \\
Arya & Male & Connected \\
Danardono & Male & Connected \\
Ms. Anna & Female & Connected \\
Andi & Male & Connected \\
\hline \hline
\end{tabular}

From the data in Table III, a test is performed on each sample examiner by giving a voice command according to an existing command. From the results of the data obtained if the person gives a clear command and the appropriate language, all can be detected.

From the results obtained in accordance with the data in Table III, it can be concluded that the application that the author has made, namely voice commands can be used by all men and women with the condition that the pronunciation of commands must be clear and the language used must be in accordance with the commands used in the application.

Next is the reliability reading test data, i.e. the extent to which applications installed on smartphones can receive input commands from users. The results of the test can be seen in the Table IV.

TABLE IV

APPLICATION RELIABILITY DATA

\begin{tabular}{cc}
\hline \hline $\begin{array}{c}\text { Speaker Distance with } \\
\text { Smartphone }\end{array}$ & Connection \\
\hline $10 \mathrm{~cm}$ & Connected \\
$30 \mathrm{~cm}$ & Connected \\
$50 \mathrm{~cm}$ & Connected \\
$70 \mathrm{~cm}$ & Connected \\
$100 \mathrm{~cm}$ & Not Connected \\
\hline \hline
\end{tabular}

Testing is done by measuring the voter, namely the measurement of the lips as a source of sound with a smartphone as a voice catcher through a microphone. From the results of the data in Table $\mathrm{IV}$, it can be concluded that the effective distance that can be used to vote is at a distance below 1 meter with a moderate voice, if by screaming it is possible to reach a greater distance.

The next test data is test data response speed of the application to control the load. The data obtained can be seen in the Table V.

TABLE V

APPLICATION RESPONSE SPEED DATA

\begin{tabular}{|c|c|}
\hline $\begin{array}{l}\text { Control by Voice } \\
\text { Command Tool }\end{array}$ & $\begin{array}{c}\text { Control with Conventional } \\
\text { Switches }\end{array}$ \\
\hline 2 Seconds & $\begin{array}{c}\text { Distance of } 3 \mathrm{~m}=3 \text { seconds } \\
\text { Distance of } 5 \mathrm{~m}=6 \text { seconds } \\
\text { Distance of } 10 \mathrm{~m}=8 \text { seconds }\end{array}$ \\
\hline
\end{tabular}

Testing is done by comparing the speed obtained from the use of sound perinth devices and conventional switches. From the data obtained in accordance with Table V, it can be concluded that using this voice command tool controlling the load will be much faster and easier, because only by giving voice commands. 
Distance testing using conventional switches is done in a walking position from the starting point to the location of the switch in a standing position, if the user's initial position is in the sleeping position or in a sitting position then to reach the switch will take more time to control the load.

\section{Conclusion}

This paper has succesed in developing the fan speed controller and lamp brightness controller with this voice command and the author then performs testing, based on the results of the manufacture and testing of the tools that have been made it can be concluded that:

1. The fan speed controller and lamp brightness with an Android-based voice command this can work well.

2. Android voice command application that has been made can work well and can be compatible with various types of Android smartphones.

3. The use of an inductive load in the form of a $220 \mathrm{~V}$ AC fan can be stable because a snubber circuit is added in the form of capacitors and resistors.

4. Controlling the 220V AC LED lamp load can not be directly carried out dimming with PWM, with the addition of the Zero crossing Detector circuit the brightness regulation of the 220V AC LED lamp can work properly.

5. Using a fan speed regulator and lamp brightness with this voice command can speed up the process of activating or deactivating the load.

6. Using this tool the fan speed and brightness of the lamp can be adjusted only by giving voice commands to the smartphone.

\section{Acknowledgements}

This work was supported by Universitas Muhammadiyah Yogyakarta.

\section{References}

[1] G. I. Pratama, "Sistem Kendali dengan Perintah Suara menggunakan Smartphone Android pada Robot Kapal berbasis Arduino," 2014.

[2] M. A. Latief, "Voice Command Pengendali Perangkat Elektronik Rumah Tangga menggunakan Raspberry Pi,” 2015.

\section{Authors' information}

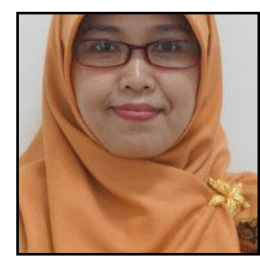

Anna Nur Nazilah Chamim obtained her B. Eng in Electrical Engineering from Universitas Muhammadiyah Yogyakarta, Indonesia. Her Master study was done at 2015 at the Electrical Engineering, Universitas Gadjah Mada, Indonesia. She currently is a lecture in department of electrical engineering, Universitas Muhammadiyah Yogyakarta.

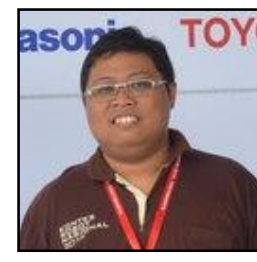

Rama Okta Wiyagi obtained his B. Eng in Electrical Engineering from Universitas Muhammadiyah Yogyakarta, Indonesia in 2009. His Master study was done at 2015 at the Electrical Engineering, Universitas Gadjah Mada, Indonesia. He currently is a lecture in department of electrical engineering, Universitas Muhammadiyah Yogyakarta.

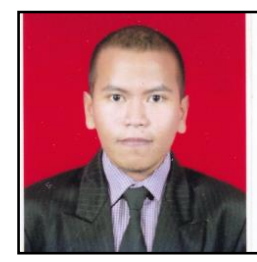

Karisma Trinanda Putra obtained his B. Eng in Electrical Engineering from Institut Teknologi Sepuluh Nopember, Indonesia in 2012. His Master study was done at 2015 at the Electrical Engineering, Institut Teknologi Sepuluh Nopember, Indonesia. He currently is a lecture in department of electrical engineering, Universitas Muhammadiyah Yogyakarta.

Faruliyan Arya Ferisnanda obtained his B. Eng in Electrical Engineering from Universitas Muhammadiyah Yogyakarta, Indonesia in 2017.

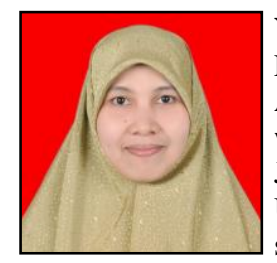

Yessi Jusman obtained her B. Eng in Electrical and Electronic Engineering from Andalas University, Indonesia in 2007. She worked as a Research Assistant started in July 2008 until November 2009 in Universiti Sains Malaysia. Her Master study was done at 2012 at the School of Electrical and Electronic Engineering, USM Engineering Campus in Nibong Tebal, Penang, Malaysia. She was finished her $\mathrm{PhD}$ degree at 2016 in University of Malaya with specializes in Image, Signal Processing, and algorithms. 